Article

\title{
Finite Element Analysis of Geogrid-Stabilized Unpaved Roads
}

\author{
Giovanni Leonardi *(D), Dario Lo Bosco, Rocco Palamara and Federica Suraci \\ DICEAM, University Mediterranea of Reggio Calabria via Graziella, Feo di Vito, 89100 Reggio Calabria, Italy; \\ dario.lobosco@unirc.it (D.L.B.); rocco.palamara@unirc.it (R.P.); federica.suraci@unirc.it (F.S.) \\ * Correspondence: giovanni.leonardi@unirc.it
}

Received: 5 December 2019; Accepted: 28 February 2020; Published: 3 March 2020

check for

updates

\begin{abstract}
The need to increase the durability of unpaved roads and the need to improve driver comfort have led to this research: to focus more attention on the use of reinforcements for this type of road. Unpaved roads are created by using an unbound granular base layer placed on compacted cohesive soils. When the subgrade is weak, due to its poor consistency and high compressibility, generally, a geosynthetic reinforcement (geogrid and/or geotextile) is placed over the subgrade, followed by a compacted granular fill layer. The use of geosynthetics can produce several benefits, such as draining, reinforcement, filtering, separation, and proofing. This paper aims to present a numerical investigation using 3-D Finite Element Modeling (FEM) to analyze the improvement, in terms of the rutting reduction of an unpaved road system, reinforced by a geogrid, under repeated traffic loads. 3-D FEM analysis was carried out on two unpaved road sections, one reinforced and the other unreinforced, with both subjected to an impulsive wheel loading. It can be concluded that a significant improvement in pavement behavior is obtained by placing a geogrid layer at the base-subgrade interface. In fact, the obtained results show that geogrid reinforcement can provide a relevant contribution to the reduction of permanent deformations.
\end{abstract}

Keywords: unpaved roads; geogrid; 3-D Finite Element Modeling (FEM)

\section{Introduction}

Low-Volume Roads (LVRs) are infrastructures with an Average Annual Daily Traffic (AADT) of $400-1000$ or fewer vehicles per day. These roads account for about $80 \%$ to $85 \%$ of the global road network (approximately 30 million kilometers of roads) [1]. A large portion of the low-volume infrastructure is unpaved (including haul roads and access roads). They are categorized as those where sand or stone aggregate is placed directly on the local subgrade soil without the application of any binder material (asphalt or cement). Hence, they derive their entire structural support through the granular base/sub-base course. Unpaved roads serve rural residents, contributing to basic access and mobility and, in some countries, they are the only type of surfacing that can be provided, due to economic constraints. When these roads are built on weak foundation soils, large deformations and different types of destresses may occur, which provoke maintenance problems in addition to safety concerns. The use of geosynthetics as a reinforcement resolves these problems and, consequently, extends the service life of the entire structure [2,3].

Geosynthetics are polymeric materials, used for several applications including filtration, drainage, protection, separation, slope stabilization, soil reinforcement and stabilization of paved or unpaved roads [4-7]. The effect of geosynthetic reinforcement depends on numerous factors, such as (i) the pavement structure, (ii) the characteristics of the materials, and (iii) the location of geosynthetics inside the layers, considering the interaction between each element [8]. Several authors have demonstrated the mechanisms of geosynthetic reinforcement and the resulting benefits in unpaved roads under 
different conditions [9-13]. The mechanisms of geosynthetics can be summarized as: (i) to restrain the lateral movement of the unbound materials (due to frictional interaction and interlocking between aggregates and the geosynthetic), (ii) to increase the stiffness and the shear strength of the unbound materials by providing additional confining stress, (iii) to improve the load distribution to the subgrade layer, and (iv) to reduce the shear stress in the subgrade (due to its stiffness, the geosynthetic exerts an upward force supporting the wheel load and thus improving the bearing capacity [14]; this is because it acts like a tensioned membrane [15]).

The geosynthetics used in an unpaved road are essentially geotextiles and geogrids. While geotextiles can be used for separation, drainage, and filtration, or as a reinforcement element, geogrids are mainly used for reinforcement applications. Geogrids are flat structures made of polymeric material (usually high-density polyethylene or polypropylene) or glass fiber. These are traditionally used in two different applications for unpaved roads: mechanical subgrade stabilization and base reinforcement [16,17].

In this paper, attention is focused on the use of geogrids as a reinforcement, which offers improved interface resistance due to interlocking (Figure 1a). This minimizes the lateral movement of aggregate particles and increases the modulus of the base course, which leads to a wider vertical stress distribution over the subgrade and consequently a reduction of vertical and lateral pavement deformations (Figure 1b) [11].

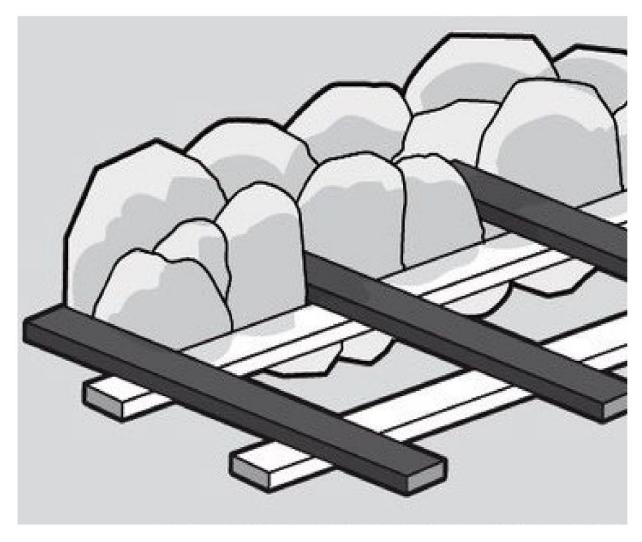

(a)

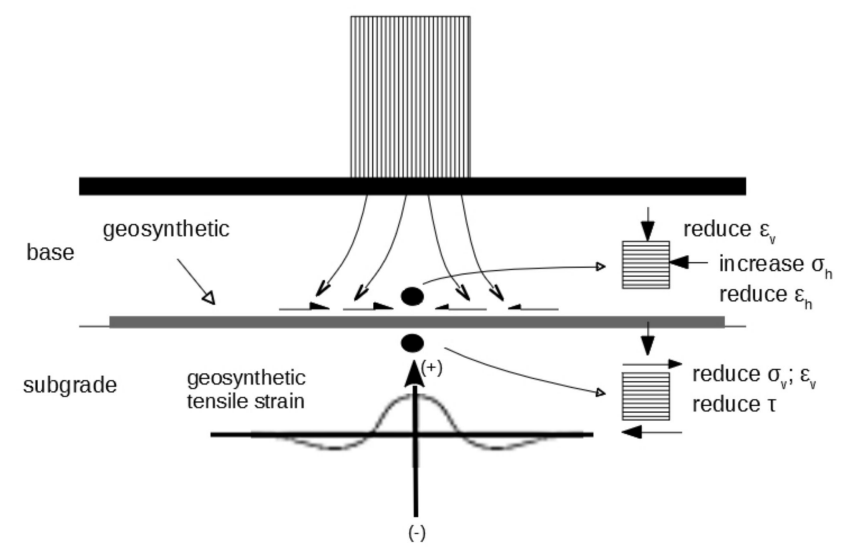

(b)

Figure 1. (a) Example of interlocking between aggregates and geogrid; (b) mechanisms of reinforcement.

As a result of interlocking, the mechanisms of reinforced unpaved structures are different for geotextiles and geogrids. There are two main reinforcement mechanisms: the lateral confinement effect and the tension membrane effect, which require different depth values of rutting in order to be mobilized. At small permanent deformation magnitudes, the lateral restraint mechanism is developed by the ability of the base aggregate to interlock with the geogrid. As the permanent deformations (which are often acceptable in unpaved roads) increase, the tension membrane mechanism develops [11]. If the geosynthetic has a sufficiently high tensile modulus, tensile stresses will be mobilized in the reinforcement, and a vertical component of this tensile membrane resistance will help to support the applied wheel loads.

Designing a gravel road reinforced with a glass fiber grid, and evaluating the effectiveness of reinforced pavement performance, is a complex problem requiring considerable research. Some studies have performed FE (Finite Element) analysis in order to demonstrate the benefits of using geosynthetics $[7,18]$. In this paper, a numerical analysis using finite element software was conducted to investigate the performance of a geogrid-reinforced aggregate over a soft subgrade. Experimental results, obtained by a triaxial test, were used in the numerical simulation for the behavior 
characterization of the base layer. The aim of this study was to quantify the contribution of geogrid reinforcement in decreasing vertical deformation due to wheel loads.

\section{Materials and Methods}

\subsection{Experimental Test}

Standard laboratory tests were carried out in order to evaluate the main geotechnical parameters of the base layer. In particular, in the Geotechnical Laboratory of DICEAM (Department of Civil Engineering, Energy, Environment and Materials at Mediterranea University), granular materials were investigated by large triaxial tests.

In this study, a granular soil was used and composed, with its grain distribution inside the upper and lower limits of particle size suggested by the South Dakota Standard Specifications for Roads and Bridges for aggregates of a base course. The material (Figure 2) was a well-graded sand with gravel (SW according to the USCS - Unified Soil Classification System, and A-1-a according to the Italian CNR-UNI 10006 classification system), with an angular grain shape, uniformity coefficient of $\mathrm{U}=\mathrm{D} 60 / \mathrm{D} 10$, equal to 31.75, and an average grain size of D50, equal to $3.1 \mathrm{~mm}$.

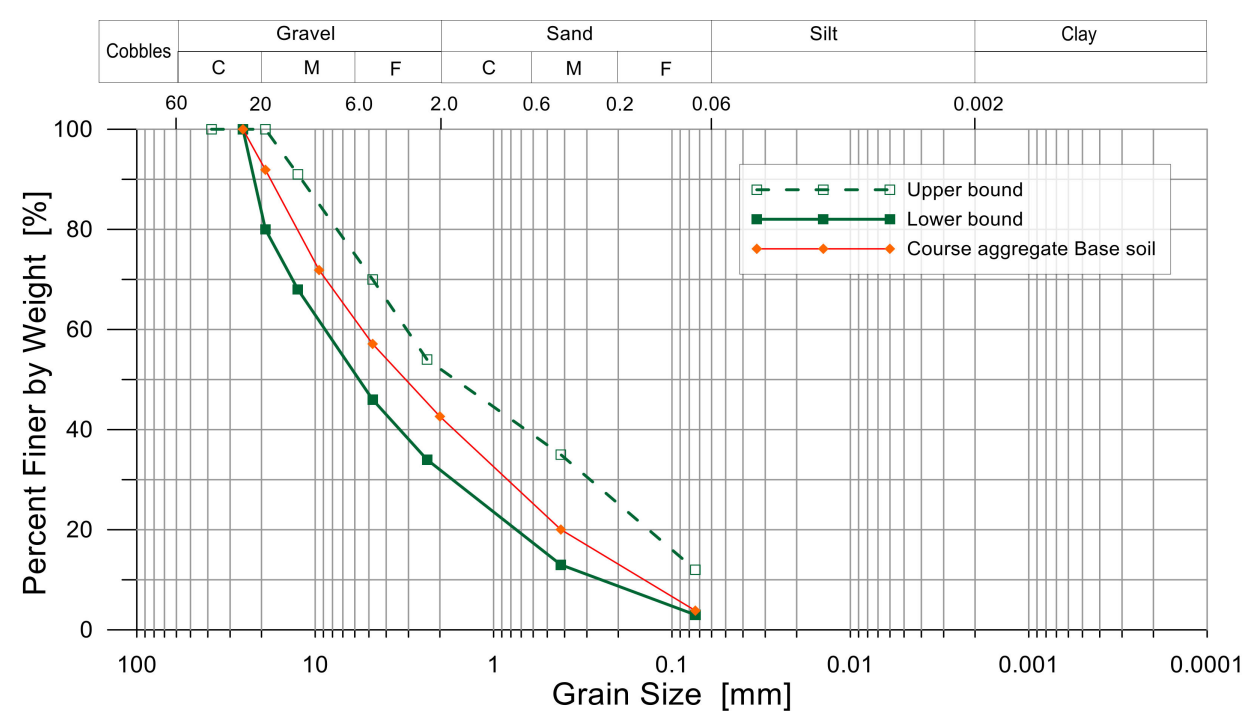

Figure 2. Gradation of the considered aggregate mixtures for the base layer.

In order to determine both the maximum and minimum index dry density/unit weight, respectively $\gamma_{\mathrm{dmax}}$ and $\gamma_{\mathrm{dmin}}$, a vertically vibrating table according to ASTM (American Society for Testing and Materials International) D4253-16e1 was used. While the $\gamma_{\text {dmax }}$ of the soil in its densest state of compactness was attained using a standard laboratory compaction procedure that minimizes particle segregation and breakdown, the $\gamma_{\mathrm{dmax}}$ of the soil in its loosest state of compactness at which it can be placed was attained using a standard procedure, which prevents bulking and minimizes particle segregation. The above compaction tests were performed on reconstructed aggregate soil, and indicated a maximum dry unit weight of $\gamma_{\mathrm{dmax}}=22.13 \mathrm{kN} / \mathrm{m}^{3}$, and a minimum dry unit weight of $\gamma_{\mathrm{dmin}}=18.25 \mathrm{kN} / \mathrm{m}^{3}$. Also, a specific gravity of soil solids, $\mathrm{G}_{\mathrm{S}}$, equal to 2.73 was obtained.

Four large triaxial tests were carried out on the aggregate specimens in order to investigate their mechanical properties. In particular, the triaxial prototype equipment, available in the DICEAM Laboratory, can perform both static and dynamic tests with a controlled stress-path. Four cylindrical samples, with a diameter equal to $200 \mathrm{~mm}$ and a height equal to $400 \mathrm{~mm}$, were prepared. The material used to produce the specimens, as aforesaid, was a well-graded sand with gravel on which, before each test, the appropriate "quartering" operations must be carried out to homogenize the particle size of the specimens. Each sample was made up of $26 \mathrm{~kg}$ of aggregates that were adequately compacted 
inside a mold in three layers. Specifically, for the preparation of the specimens, the soil was encased by a latex membrane in order to avoid contact with water in the cylindrical chamber. The specimen was prepared in successive steps by a defined operation of wet tamping. This procedure consists of regularly compacting layers of damp soil of a constant height. The weight of the material with which to form the $\mathrm{i}^{\text {th }}$ layer depends on the height of the single-layer and the desired relative density. The compaction is carried out by dropping a pestle on the ground sample from a predetermined height (304.8 $\mathrm{mm}$ ) (Figure 3a). The sample is divided into three layers in order to make a homogeneous compaction and to reduce the number of strokes for each level.

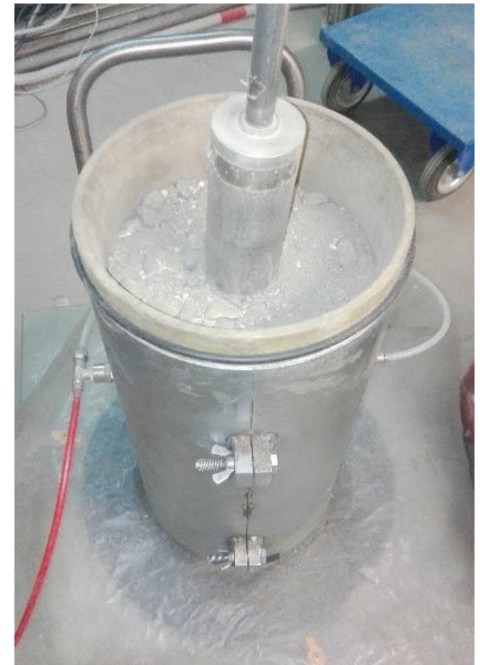

(a)

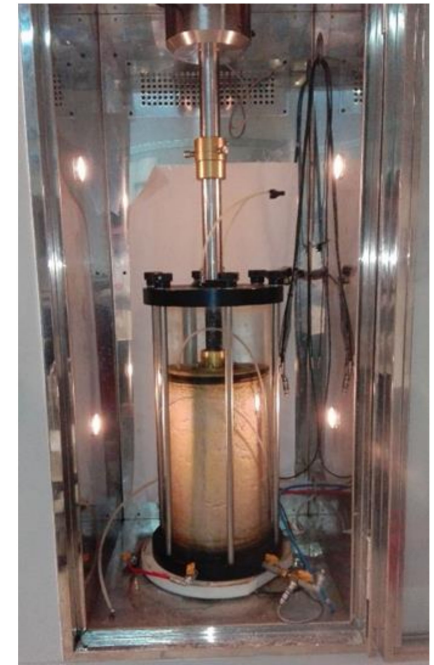

(b)

Figure 3. (a) Soil specimen; (b) connection of the soil specimen with drainage tubes and mold removal.

The specimen was completed by leveling the upper side and then introducing the filter paper, the porous stone, and the loading plate. In order to remove the mold without the specimen collapsing, a depression was applied so that the latex membrane adhered completely to the specimen surface; then, the mold was removed and the specimen was set in the test chamber. Subsequently, drainages, which allow for the sample saturation phase, were connected in both the upper side and the lower side. Once the assembly phase of the triaxial chamber was completed, the supports for the LVDT (Linear Variable Differential Transformer) axial sensors were inserted (Figure 3b).

The triaxial tests were carried out by varying the confining pressure (50, 100 and $150 \mathrm{kPa})$. The results of the test were used to determine the parameters of the granular materials required for the numerical simulations (Table 1).

Table 1. Materials data and model parameters used in the Finite Element Modeling (FEM) analysis.

\begin{tabular}{ccccc}
\hline Materials & $\begin{array}{c}\text { Model and Parameters } \\
\text { (Drucker-Prager) }\end{array}$ & $\begin{array}{c}\text { Yield Stress } \\
\mathbf{( k P a )}\end{array}$ & $\begin{array}{c}\mathbf{E} \\
\mathbf{( M P a )}\end{array}$ & $\boldsymbol{v}$ \\
\hline base & $\beta=40^{\circ}, \psi=10^{\circ}$ & 150 & 50 & 0.35 \\
subgrade & $\beta=10^{\circ}, \psi=0^{\circ}$ & 43.6 & 10 & 0.42 \\
\hline
\end{tabular}

The subgrade parameters required for the simulations in the FE analysis, listed in Table 1, were assumed to be realistic, as much as possible, as published in previous studies [18].

\subsection{Finite Element Model}

The considered unpaved road section had the following dimensions: $5 \mathrm{~m}$ in the $\mathrm{x}$ - and $\mathrm{y}$-directions, and $3.5 \mathrm{~m}$ in the $\mathrm{z}$-direction. Figure 4a presents a sketch of the pavement structure geometry with the model dimension. 


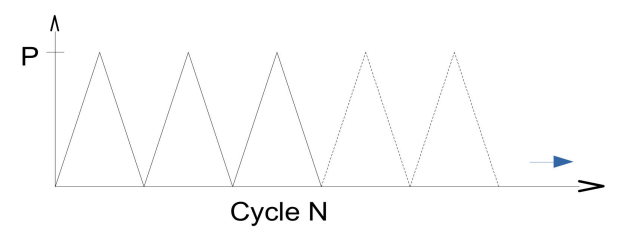

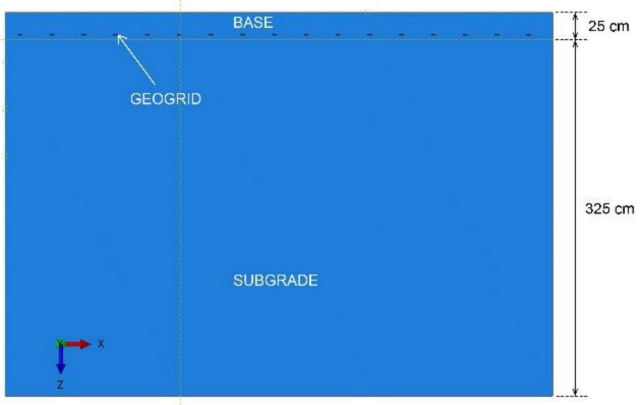

(a)

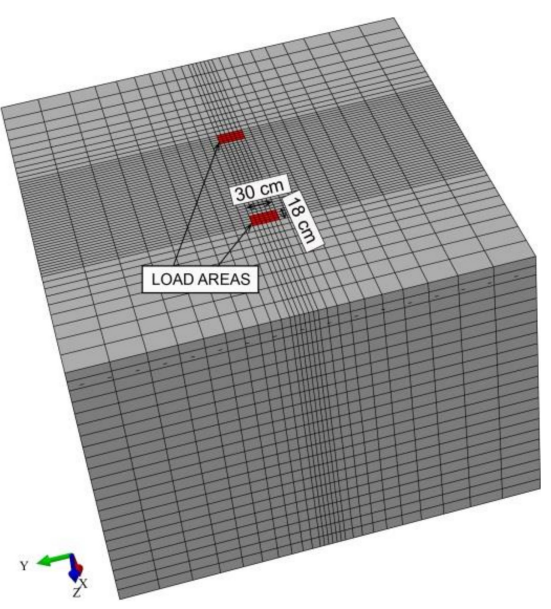

(b)

Figure 4. (a) Schematic repeated loading and sketch of the pavement geometry; (b) three-dimensional view of the finite element model showing the area of applied loads.

In the proposed numerical simulation, a Drucker-Prager model was used for the base and the subgrade layers. For the geogrid, instead, a linear elastic constitutive model was used to describe the behavior of geogrid material $(\mathrm{E}=760 \mathrm{MPa} ; v=0.30)$. Such a model proved to be efficient when used by other researchers $[19,20]$, especially since the induced strain in the geogrid is very small and is considered within the elastic range.

To simulate heavy vehicular traffic, a cyclic load of triangular type [21-24], with an amplitude equal to $40 \mathrm{kN}$ (resulting in a pavement pressure of $550 \mathrm{kPa}$ ) and number of cyclic repetitions (Ncycles) equal to 2000, was applied over a rectangular area (Figure 4b). Within each cycle, the load was applied with a duration time of $0.01 \mathrm{sec}$ in order to simulate vehicle speed.

The model was constrained at the bottom; along the sides parallel to the y-axis, all nodes were constrained horizontally but were free to move in a vertical direction. The boundary nodes along the pavement edges parallel to the $x$-axis were free in both the horizontal and vertical directions. Different FE analyses on models with different boundary conditions at the edges parallel to the $x$ - and $y$-axes were performed to examine the boundary effect. No significant effect was found on surface deformations.

All layers were considered perfectly bonded to one another so that the nodes at the interface of the two layers had the same displacements in all three $(x, y, z)$ directions. Assuming a perfect bond at the layer interfaces implied that there would be no slippage at the interface.

The degree of mesh refinement was the most important factor in estimating an accurate stress field in the pavement: the finest mesh was required near the loads to capture the stress and strain gradients. The mesh presented has 35,397 nodes and 30,237 elements (linear hexahedron, type C3D8R). In the reinforced section, the glass fiber grid was simulated by a 3-D deformable shell planar (membrane elements section type) with a thickness of $0.003 \mathrm{~m}$ and with open meshes (Figure 5a). The membrane effect of the geogrid was characterized by assigning the geogrid material as a membrane element.

The soil-geogrid interaction was established by creating two contact surface pairs above and below the geogrid layer. The results of previous studies $[7,25]$ indicated that using the surface-to-surface contact model with the traditional node-to-surface contact formulation is suitable to define such a contact condition between the (soil) solid elements and the (geogrid) membrane elements.

The ABAQUS contact interaction feature was used in this study to model the geogrid-soil interface. With this feature, one surface definition provides the "master" surface, and the other surface definition provides the "slave" surface. The master surface is used for a rigid body surface, while the slave 
surface is used for a deformable body surface. The interaction simulation consists of two components: one normal to the surfaces and one tangential to the surfaces. The interface in the normal direction is assumed to be a "hard contact", and no separation is allowed. Meanwhile, in the tangential direction, full interlocking was assumed between the geogrid layer and the material surrounding it, as shown in the pattern given in Figure 5b. This was done by using the tie-condition in the ABAQUS interaction feature, where each node of the slave surface (geogrid) is tied to the nearest node on the master surface [25-27].

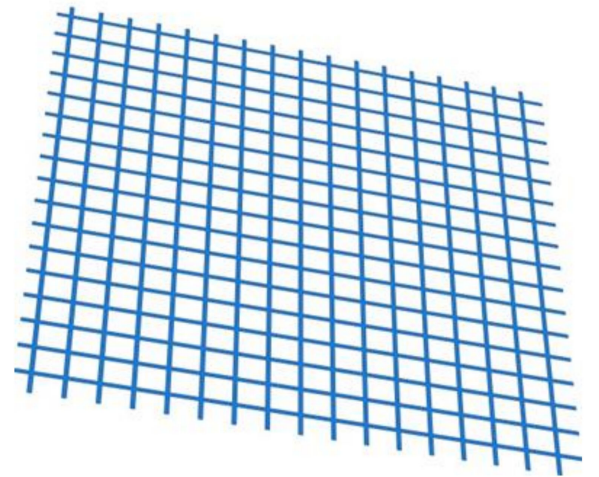

(a)

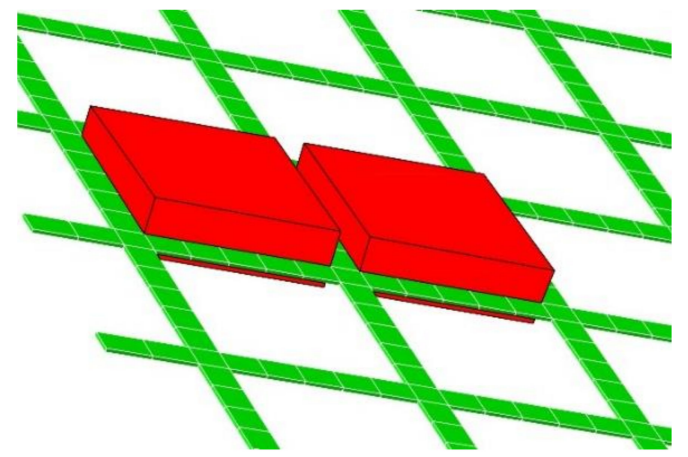

(b)

Figure 5. (a) Geogrid model; (b) soil-geogrid interlocking.

\section{Results and Discussion}

The following figures show the results of these simulations, where the vertical displacements were considered a response to the application of repeated loads.

In detail, Figure $6 \mathrm{a}, \mathrm{b}$ show, respectively, the deformed configuration for the unreinforced unpaved section and the reinforced unpaved section. The final vertical displacements under the load center, after 2000 cycles of loading, were respectively about $22 \mathrm{~mm}$ and $16 \mathrm{~mm}$.

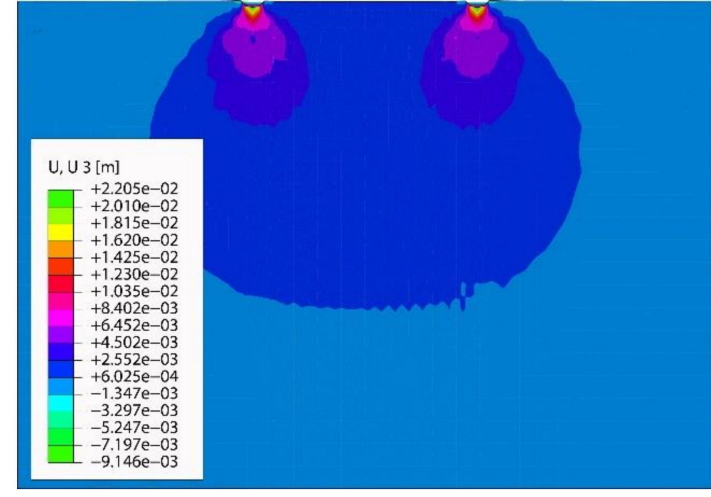

(a)

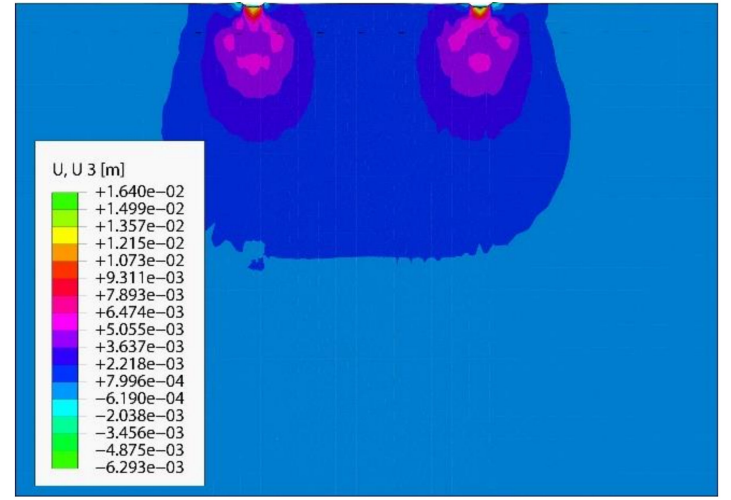

(b)

Figure 6. Deformed configuration and vertical displacements after 2000 load cycles: (a) unreinforced unpaved section; (b) reinforced unpaved section.

In detail, Figure 7 shows the vertical displacements profile across the transverse section under the center of one load area. The presence of the geogrid implies an improvement in terms of surface displacement reduction, corresponding to $25 \%$ after 2000 loading cycles.

Similarly, Figure 8 shows the vertical displacements profile of the subgrade layer surface across the transverse section under the center of one load area. It is noted from Figures 7 and 8 that the inclusion of the geogrid resulted in a significant reduction in the vertical deformation at the top of the 
pavement, and this kind of reduction decreased with the increase in the distance from the top of the pavement to the subgrade surface [26].

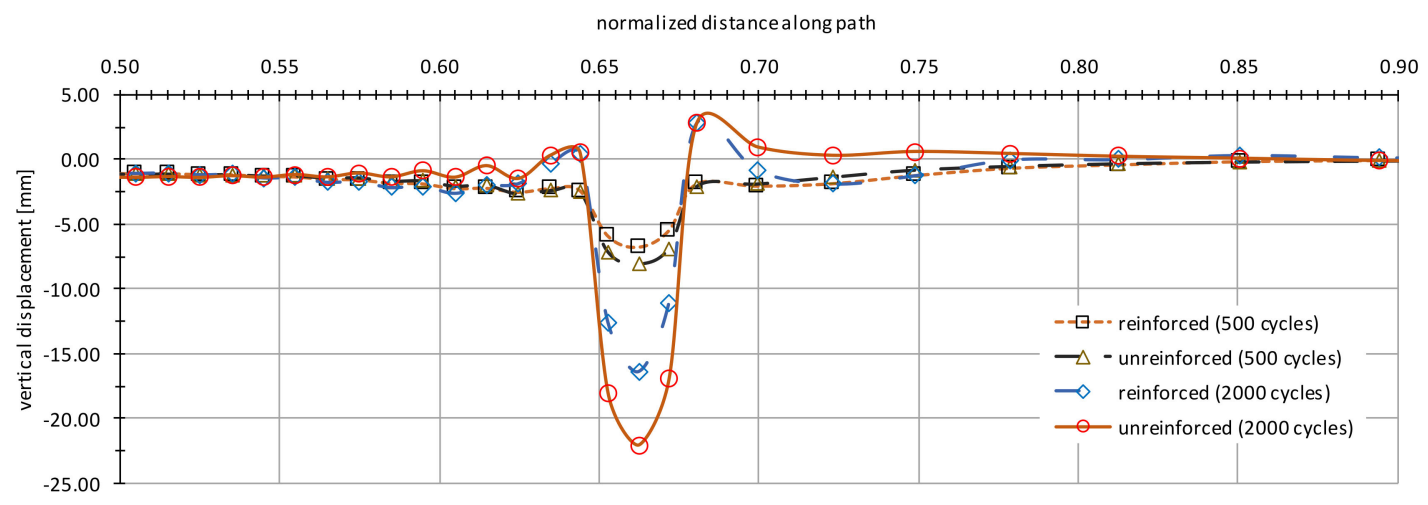

Figure 7. Vertical displacements profile of the base layer surface after 500 and 2000 load cycles for unreinforced and reinforced unpaved sections.

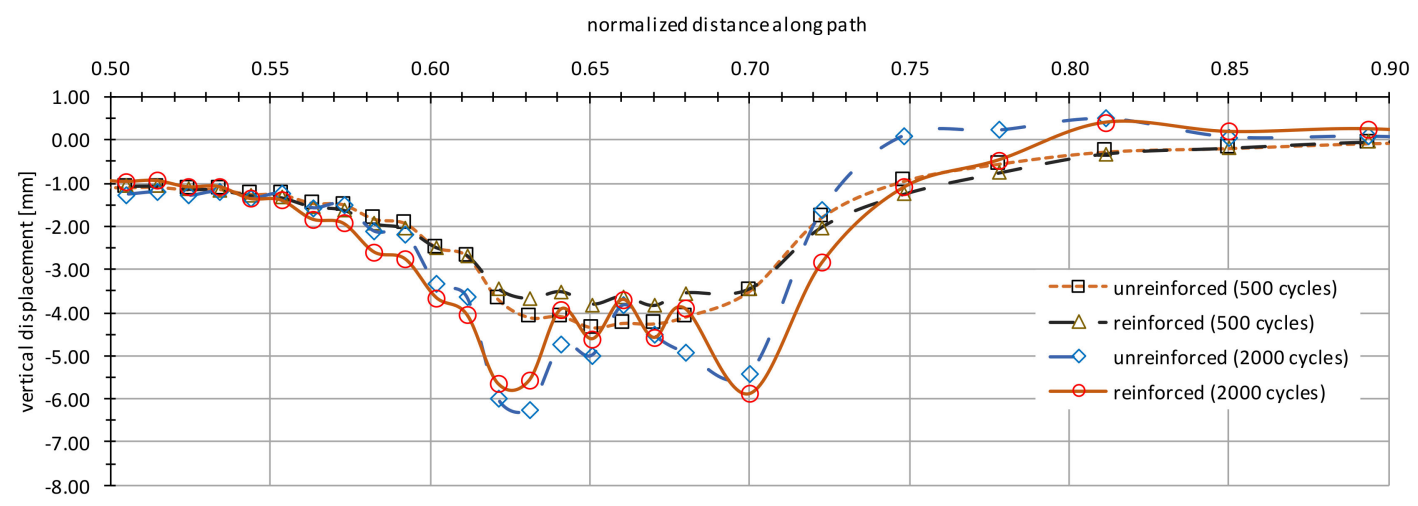

Figure 8. Vertical displacements profile of the subgrade layer surface after 500 and 2000 load cycles for unreinforced and reinforced unpaved sections.

Figure 9 illustrates that the maximum vertical deformation increases with an increase in the number of loading cycles. In particular, comparing the unreinforced unpaved section with the corresponding reinforced one, it is possible to observe an increasing improvement in terms of the reduction of rutting, which means an important increase in the service road life.

Therefore, these simulation results show that the proposed model has the capability to capture the unbounded pavement responses under repeated loads. This aspect is very important because several agencies have adopted rutting as a failure criterion in pavement design.

Figure 10 shows the Mises stress distribution in the pavement section. These results indicate the influence of reinforcement also in pavement behavior, with a reduction of the peak value of Mises stress, as shown in the figures below.

Finally, the 3-D geometry of the geogrid, its deformation, and its stress distribution are presented in Figure 11. Increasing the number of loading cycles resulted in an increase in the geogrid vertical deformations and in the Mises stresses. The above example demonstrates that the proposed approach is suitable for solving geogrid-reinforced unpaved road systems. The results showed that the model could capture the essential interlocking and friction mechanisms, which allows for the response of these systems to be evaluated. 


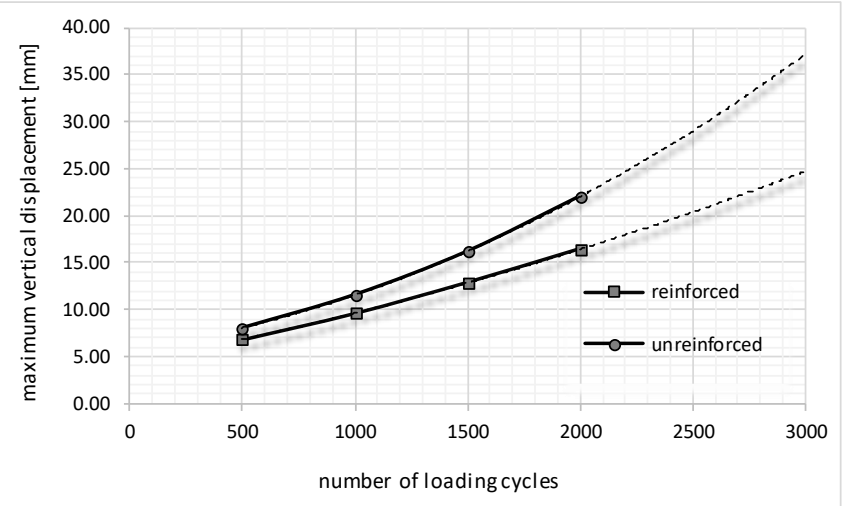

Figure 9. Relationship between the number of cycles and the maximum vertical displacement of the pavement surface.

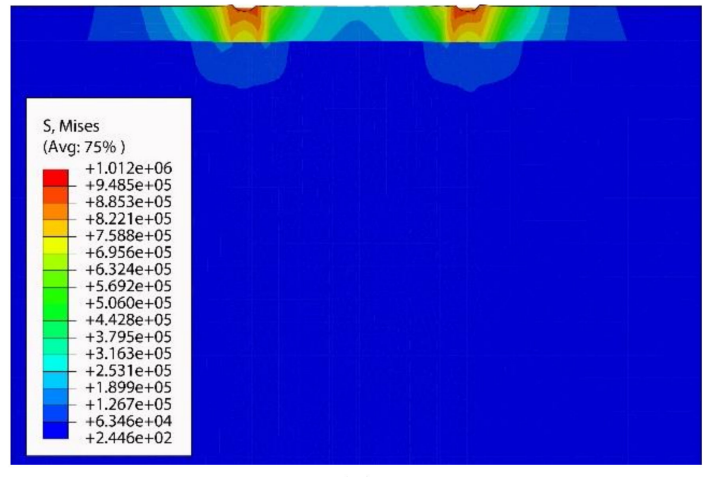

(a)

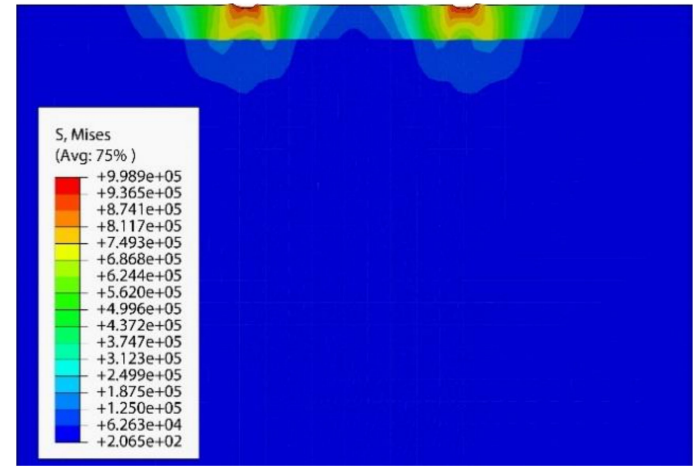

(b)

Figure 10. Mises stress (Pa) distribution after 2000 load cycles: (a) unreinforced unpaved section; (b) reinforced unpaved section.

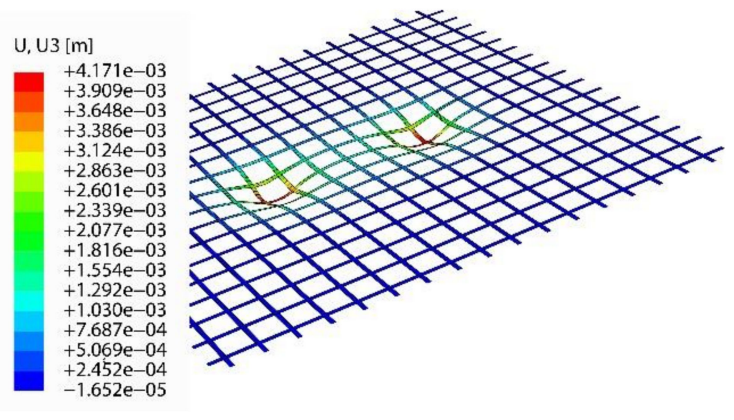

$\mathrm{N}=500$

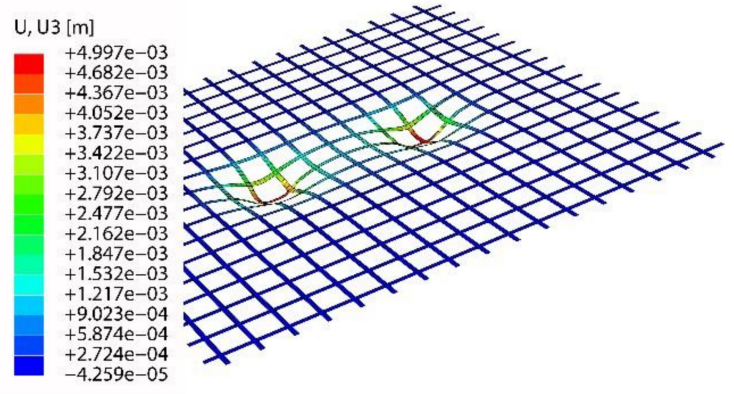

$\mathrm{N}=1000$

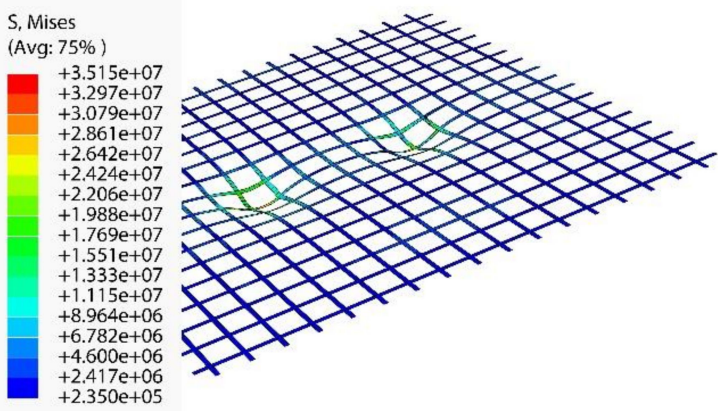

$\mathrm{N}=500$

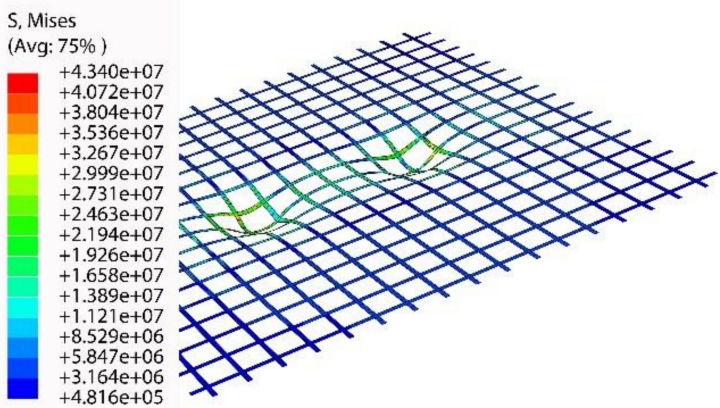

$\mathrm{N}=1000$

Figure 11. Cont. 

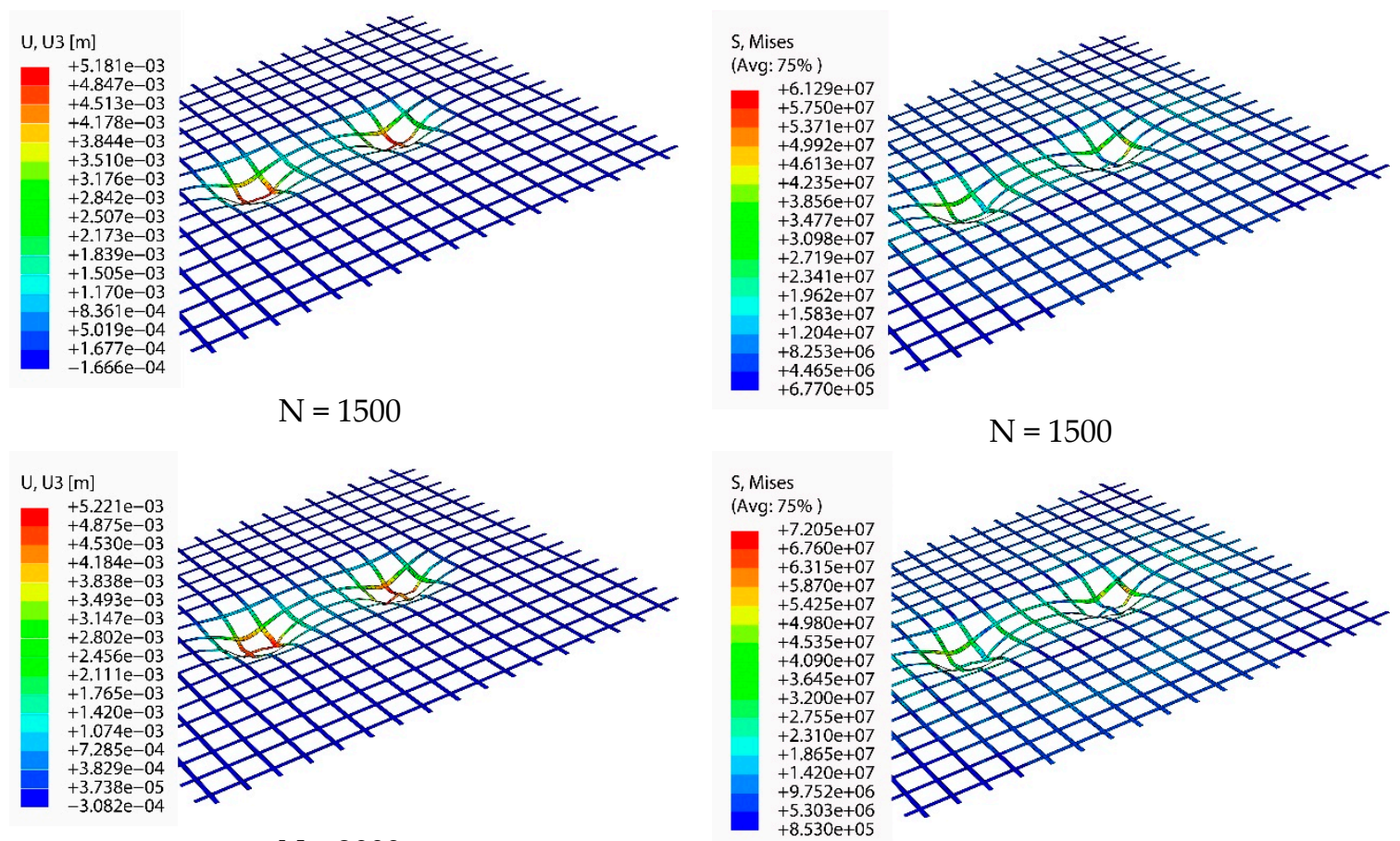

$\mathrm{N}=2000$

(a)

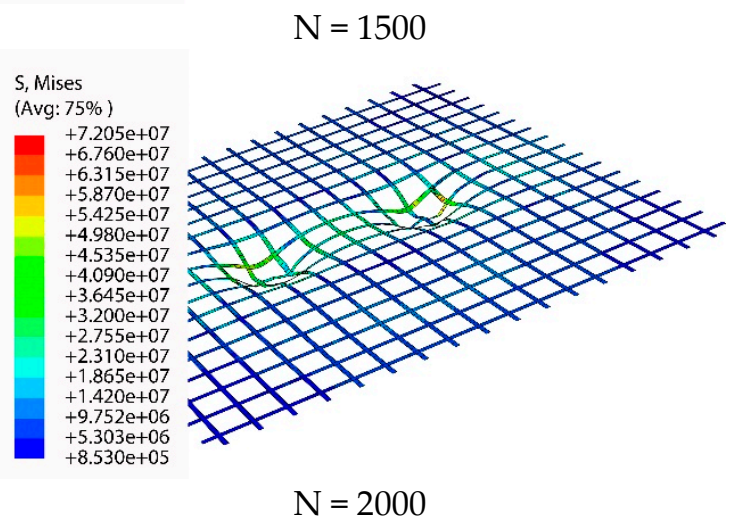

(b)

Figure 11. (a) Geogrid vertical deformation after N loading cycles; (b) geogrid Mises stress distribution (Pa) after $\mathrm{N}$ loading cycles.

\section{Conclusions}

This paper aimed to analyze the improvement of an unpaved road system reinforced by a glass fiber grid, under repeated wheel traffic load conditions, only in terms of the reduction of rutting. The reason to consider only this kind of distress is that the numerical investigation by FEM cannot provide information relating to the extent of cracking under the action of repeated vehicular loadings. On the other hand, FE analysis is a powerful tool to predict rut depth, taking into account the reinforcement stiffness, interface properties, and geometrical and mechanical properties of each layer that composes the road section (i.e., HMA - hot mix asphalt, base, sub-base and subgrade), and finally traffic conditions.

On the basis of the 3-D FE analysis, carried out by ABAQUS software, it can be concluded that an improvement in pavement behavior is obtained by placing a glass fiber grid layer at the base-subgrade interface. Particularly, under the same traffic conditions (i.e., Ncyclic $=2000$ ) and geometrical and mechanical properties of all the pavement layers, the reinforced configuration works better compared to the unreinforced one. Thus, this evidence demonstrates that the model is able to capture the pavement behavior under repeated vehicular loads. From an economic point of view, the effectiveness of using geosynthetic reinforcement to reduce the superficial permanent rut deformations for a given number of axle loads, in comparison with the traditional configuration, leads to an increase in the road service life, and, at the same time, to a decrease in the number of periodic maintenance interventions.

Therefore, FEM analysis results could be important to quantify the benefit-cost ratio of geosynthetics application in pavements needed for a detailed Life-Cycle Cost Analysis (LCCA), which should include the initial construction, maintenance, and user costs. Since LCCA is a useful economic tool in considering certain transportation investment decisions, this topic could be another potential research subject.

Author Contributions: The co-authors together equally contributed to the completion of this article. All authors have read and agreed to the published version of the manuscript. 
Funding: This research received no external funding.

Conflicts of Interest: The authors declare no conflict of interest.

\section{References}

1. Faiz, A.J. The promise of rural roads: Review of the role of low-volume roads in rural connectivity, poverty reduction, crisis management, and livability. In Transportation Research Circular; Transportation Research Board: Washington, DC, USA, 2012; Volume Circular E-C167.

2. Calvarano, L.S.; Palamara, R.; Leonardi, G.; Moraci, N. Unpaved Road Reinforced with Geosynthetics. Procedia Eng. 2016, 158, 296-301. [CrossRef]

3. Calvarano, L.; Palamara, R.; Leonardi, L.; Moraci, N. Proceedings of the 6th European Geosynthetics Congress Proceedings Reinforced Unpaved Roads: Parametrical Analysis of Design Procedures_EUROGEO 6, Ljubljana, Slovenia, 7 July 2016.

4. Buonsanti, M.; Leonardi, G.; Scopelliti, F. Theoretical and computational analysis of airport flexible pavements reinforced with geogrids. In 7th RILEM International Conference on Cracking in Pavements; Springer: Dordrecht, The Netherlands; Berlin/Heidelberg, Germany, 2012; pp. 1219-1227.

5. Buonsanti, M.; Leonardi, G. FEM analysis of airport flexible pavements reinforced with geogrids. Adv. Sci. Lett. 2012, 13, 392-395. [CrossRef]

6. Leonardi, G. Finite element analysis for airfield asphalt pavements rutting prediction. Bull. Pol. Acad. Sci. Tech. Sci. 2015, 63, 397-403. [CrossRef]

7. Calvarano, L.S.; Leonardi, G.; Palamara, R. Finite element modelling of unpaved road reinforced with geosynthetics. Procedia Eng. 2017, 189, 99-104. [CrossRef]

8. Suraci, F.; Buonsanti, M.; Leonardi, G.; Palamara, R. A FEM Simulation of the Mechanical Interaction between Asphalt Mixture and Geogrid at Micro-Scale. Key Eng. Mater. 2018, 774, 595-600. [CrossRef]

9. Fannin, R.J.; Sigurdsson, O. Field observations on stabilization of unpaved roads with geosynthetics. J. Geotec. Eng. 1996, 122, 544-553. [CrossRef]

10. Leng, J.; Gabr, M.A. Characteristics of Geogrid-Reinforced Aggregate Under Cyclic Load. Transp. Res. Rec. 2002, 1786, 29-35. [CrossRef]

11. Giroud, J.P.; Han, J. Design method for geogrid-reinforced unpaved roads. I. Development of design method. J. Geotech. Geoenvironmental Eng. 2004, 130, 787-797. [CrossRef]

12. Perkins, S.; Christopher, B.; Lacina, B.; Klompmaker, J. Mechanistic-empirical modeling of geosynthetic-reinforced unpaved roads. Int. J. Geomech. 2011, 12, 370-380. [CrossRef]

13. Han, B.; Ling, J.; Shu, X.; Song, W.; Boudreau, R.L.; Hu, W.; Huang, B. Quantifying the effects of geogrid reinforcement in unbound granular base. Geotext. Geomembr. 2019, 47, 369-376. [CrossRef]

14. Perkins, S.W. Mechanical response of geosynthetic-reinforced flexible pavements. Geosynth. Int. 1999, 6, 347-382. [CrossRef]

15. Kawalec, J.; Grygierek, M.; Koda, E.; Osiński, P. Lessons Learned on Geosynthetics Applications in Road Structures in Silesia Mining Region in Poland. Appl. Sci. 2019, 9, 1122. [CrossRef]

16. Kim, D.; Ha, S. Effects of Particle Size on the Shear Behavior of Coarse Grained Soils Reinforced with Geogrid. Materials 2014, 7, 963-979. [CrossRef] [PubMed]

17. Holtz, R.D. Geosynthetics for soil reinforcement. In The Ninth Spencer J. Buchanan Lecture; College Station Hilton: College Station, TX, USA, 2001.

18. Leng, J.; Gabr, M.A. Numerical analysis of stress-deformation response in reinforced unpaved road sections. Geosynth. Int. 2005, 12,111-119. [CrossRef]

19. Ling, H.I.; Liu, H. Finite Element Studies of Asphalt Concrete Pavement Reinforced with Geogrid. J. Eng. Mech. 2003, 129, 801-811. [CrossRef]

20. Perkins, S. Mechanistic-Empirical Modeling and Design Model Development of Geosynthetic Reinforced Flexible Pavements; Final Report; Montana State University: Bozeman, MT, USA, 2001.

21. Al Khateeb, L. Rutting Prediction of Flexible Pavements Using Finite Element Modeling. Jordan J. Civ. Eng. 2011, 5, 173-190.

22. Gao, L.-S.; Dan, H.-C.; Li, L. Response Analysis of Asphalt Pavement under Dynamic Loadings: Loading Equivalence. Math. Probl. Eng. 2019, 2019, 15. [CrossRef] 
23. Saad, B.; Mitri, H.; Poorooshasb, H.J.J. Three-dimensional dynamic analysis of flexible conventional pavement foundation. J. Transp. Eng. 2005, 131, 460-469. [CrossRef]

24. Wu, Z.; Chen, X. Prediction of permanent deformation of pavement base and subgrade materials under accelerated loading. Int. J. Pavement Res. Technol. 2011, 4, 231-237.

25. Hussein, M.G.; Meguid, M.A. Three-Dimensional Finite Element Analysis of Soil-Geogrid Interaction under Pull-out Loading Condition. In GeoMontreal 2013, the 66th Canadian Geotechnical Conference; McGill University: Montreal, QC, Canada, 2013; Volume 1, pp. 452-458.

26. Abu-Farsakh, M.Y.; Gu, J.; Voyiadjis, G.Z.; Chen, Q. Mechanistic-empirical analysis of the results of finite element analysis on flexible pavement with geogrid base reinforcement. Int. J. Pavement Eng. 2014, 15, 786-798. [CrossRef]

27. Hussein, M.G.; Meguid, M.A. A three-dimensional finite element approach for modeling biaxial geogrid with application to geogrid-reinforced soils. Geotext. Geomembr. 2016, 44, 295-307. [CrossRef]

(C) 2020 by the authors. Licensee MDPI, Basel, Switzerland. This article is an open access article distributed under the terms and conditions of the Creative Commons Attribution (CC BY) license (http://creativecommons.org/licenses/by/4.0/). 